Article

\title{
Antimicrobial Susceptibility and Antibacterial Mechanism of Limonene against Listeria monocytogenes
}

\author{
Yingjie Han, Zhichang Sun * and Wenxue Chen * \\ College of Food Sciences \& Engineering, Hainan University, 58 People Road, Haikou 570228, China; \\ 18085231210009@hainanu.edu.cn \\ * Correspondence: 13919003678@163.com (Z.S.); hnchwx@163.com (W.C.)
}

Received: 24 October 2019; Accepted: 12 December 2019; Published: 20 December 2019

check for updates

\begin{abstract}
Limonene is a monoterpenoid compound, which is founded in a lot of plants' essential oils with good antibacterial activity against food-borne pathogens, but it has an ambiguous antimicrobial susceptibility and mechanism against Listeria monocytogenes (L. monocytogenes). In this study, the antimicrobial susceptibility of Limonene to L. monocytogenes was studied, and some new sights regarding its antibacterial mechanism were further explored. Scanning electron MICroscopy (SEM) verified that limonene caused the destruction of the cell integrity and wall structure of $L$. monocytogenes. The increase in conductivity and the leakage of intracellular biomacromolecules (nucleic acids and proteins) confirmed that limonene had an obvious effect on cell membrane permeability. The results of Propidium Iodide (PI) fluorescence staining were consistent with the results of the conductivity measurements. This indicated that limonene treatment caused damage to the L. monocytogenes cell membrane. Furthermore, the decrease in ATP content, ATPase $\left(\mathrm{Na}^{+} \mathrm{K}^{+}\right.$-ATPase, $\mathrm{Ca}^{2+}$-ATPase $)$ activity and respiratory chain complex activity indicated that limonene could hinder ATP synthesis by inhibiting the activity of the respiratory complex and ATPase. Finally, differential expression of proteins in the respiratory chain confirmed that limonene affected respiration and energy metabolism by inhibiting the function of the respiratory chain complex.
\end{abstract}

Keywords: Limonene; antibacterial mechanism; membrane damage; nucleic acid; protein; ATP; ATPase; respiratory complexes

\section{Introduction}

Food-borne pathogens are one of the main causes of foodborne diseases and they have become an important public health problem threatening people's health [1]. The Gram-positive bacterium L. monocytogenes is widely distributed in a variety of foods (meat, aquatic products, dairy products, vegetables, etc.) [2] and it is one of the most common zoonotic foodborne pathogens that can invade the body by food chain, causing meningitis, myocarditis, sepsis, premature birth, and other diseases in humans and livestock [3]. In addition, L. monocytogenes has a strong adaptability to environments. For example, it can survive at cold storage temperatures, in low $\mathrm{pH}$ values and in high salt concentrations [4]. Therefore, controlling the L. monocytogenes pollution is a major issue in the face of food safety [5]. In response to L. monocytogenes contamination, a variety of different antimicrobial agents have been used in recent years. Among them, natural antimicrobial agents have become the focus [6].

Essential oils are considered to be potential natural food preservatives and antimicrobial agents and have been widely used in food preservation [7]. It was reported that terpenoids were an important component of essential oils [8]. Limonene (1-methyl-4-(1-methylethenyl) is one of the most common 
terpenes in nature and is widely found in the volatile oils of various plants (black pepper, lemon and orange, etc.) [9]. Limonene has broad application prospects in antibacterial and food preservation due to its broad-spectrum bactericidal activity, safety, and low toxicity [10]. Moreover, D-limonene can significantly inhibit gram-negative and gram-positive bacteria as well as fungal activity [11]. In addition, many researchers have confirmed that D-limonene can effectively inhibit the growth of spoilage bacteria, such as Aspergillus niger, Pseudomonas aeruginosa, Staphylococcus aureus, and Escherichia coli [12,13]. Limonene, which is the main ingredient of lemon essential oil, was found to have antimicrobial activities against L. monocytogenes in minced beef meat [14]. However, few studies have investigated the antibacterial mechanism of limonene.

The aims of this study were to determine the antibacterial susceptibility and its antibacterial mechanism of limonene against $L$. monocytogenes. The minimum inhibitory concentration (MIC) was used to evaluate the anti-L. monocytogenes susceptibility of limonene. The growth curves of the bacterial were determined for evaluating the effect of limonene on the growth and reproduction of L. monocytogenes. The mechanism of action of limonene was explored by analysing its influence on the cell morphology, membrane permeability and changes in the protein, nucleic acid, ATP, ATPase $\left(\mathrm{Na}^{+} \mathrm{K}^{+}\right.$-ATPase, $\mathrm{Ca}^{2+}$-ATPase), respiratory chain complex I $\sim$, and differential protein expression of the respiratory chain complex of L. monocytogenes.

\section{Results}

\subsection{Antibacterial Susceptibility and Determination of the Growth Curves of L. monocytogenes}

\subsubsection{Determination of minimum Inhibitory Concentration (MIC)}

As shown in Table 1, sterile water and $20 \%$ ethanol had no effect on bacterial growth. Limonene and positive control (Levofloxacin Hydrochloride) can both significantly inhibit bacterial reproduction, and antimicrobial abilities increased with increasing drug concentration. In addition, bacteria did not grow when the concentration of limonene was $20 \mathrm{~mL} / \mathrm{L}$. Therefore, the MIC of limonene was $20 \mathrm{~mL} / \mathrm{L}$. Meanwhile, the bacteria were inhibited by $0.625 \mathrm{~mL} / \mathrm{L}$ of Levofloxacin Hydrochloride. Therefore, the MIC of Levofloxacin Hydrochloride was $0.625 \mathrm{~mL} / \mathrm{L}$. In general, limonene was less susceptible than Levofloxacin Hydrochloride against L. monocytogenes.

Table 1. Minimum inhibitory concentration (MIC) of limonene against L. monocytogenes.

\begin{tabular}{|c|c|c|c|c|c|c|c|c|c|}
\hline \multirow{2}{*}{ Treatment } & \multicolumn{9}{|c|}{ Concentration of Drugs $(\mathrm{mL} / \mathrm{L})$} \\
\hline & & 0.3125 & 0.625 & 1.25 & 2.5 & 5 & 10 & 20 & 40 \\
\hline Limonene & & +++ & +++ & +++ & +++ & +++ & ++ & - & - \\
\hline Levofloxacin Hydrochloride & & + & - & - & - & - & - & - & - \\
\hline Sterile water & +++ & & & & & & & & \\
\hline $20 \%$ Ethanol & +++ & & & & & & & & \\
\hline
\end{tabular}

\subsubsection{Bacterial Growth Curves of L. monocytogenes}

Figure 1 shows the growth curves of L. monocytogenes and they were determined by measuring the optical density at $600 \mathrm{~nm}$. The growth curves of L. monocytogenes included four phases: lag phase (the preparatory phase for the beginning of a split), logarithmic phase (a phase of logarithmic increase in the number of bacteria), stationary phase (a phase of equilibrium in bacterial concentration), and decline phase (a phase in which the total viable count decreased significantly). As shown in Figure 1, the growth curves of the L. monocytogenes in the control groups showed an " $\mathrm{S}$ " trend. The L. monocytogenes of the blank control group and ethanol group both reached the logarithmic phase after $4 \mathrm{~h}$, reaching their maximum at $17 \mathrm{~h}$. In addition, they almost simultaneously reached the stationary phase, which indicated that $20 \%$ ethanol had no significant effect on bacterial growth $(p>$ 0.05). However, the OD600 of the bacterial fluid that was treated with limonene (1 MIC and 2 MIC) 
was critically lower than that of the control groups, and the growth of L. monocytogenes almost stopped. The minimum limonene concentration that can inhibit bacterial growth and reproduction is defined as 1 MIC. Double the minimum concentration of limonene that inhibits bacterial growth and reproduction is defined as $2 \mathrm{MIC}$.

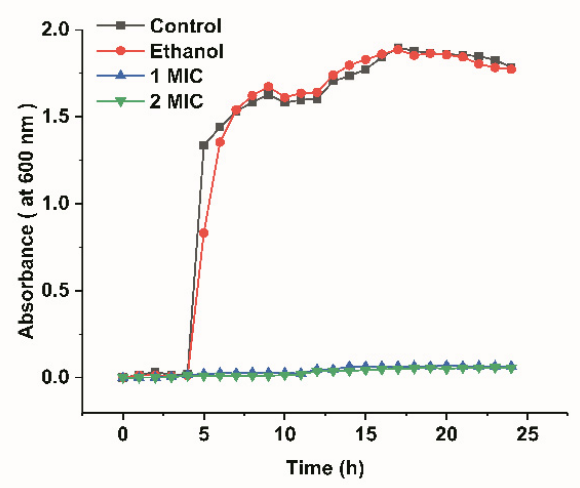

Figure 1. Growth curves of L. monocytogenes.

\subsection{Antibacterial Mechanism}

\subsubsection{Effect of Limonene on the Cell Morphology of L. monocytogenes}

The cells in the blank control group and negative control group were intact and smooth, and no cell damage occurred, as shown in Figure 2, $\mathrm{t}$ (Figure $2 \mathrm{a}-\mathrm{d}$ ). In contrast, bacterial cells that were treated with limonene at $1 \mathrm{MIC}$ and $2 \mathrm{MIC}$ for $6 \mathrm{~h}$ and $12 \mathrm{~h}$ at $37^{\circ} \mathrm{C}$ were subjected to considerable damage (Figure 2e,f). The cells that were exposed to limonene (1 MIC) for $6 \mathrm{~h}$ showed a dramatic morphological change, with alterations in shape and unclear cell boundaries (Figure 2e). As the treatment time was prolonged to $12 \mathrm{~h}$, the cells showed severe ruptures and holes and severe aggregation and overlap (Figure 2f). Moreover, the cells that were treated with limonene at 2 MIC were more badly hurt than those that were treated with limonene at $1 \mathrm{MIC}$ for $6 \mathrm{~h}$ (Figure $2 \mathrm{~g}$ ) and even completely dissolved at $12 \mathrm{~h}$ (Figure 2h).
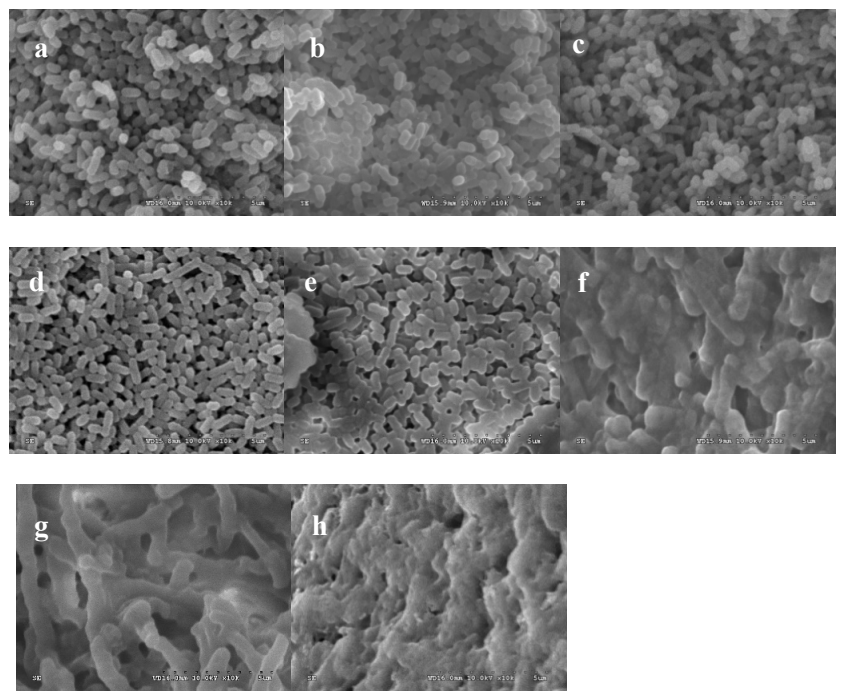

Figure 2. Scanning electron MICrophotographs of L. monocytogenes. Cells without treatment for $6 \mathrm{~h}$ (a),

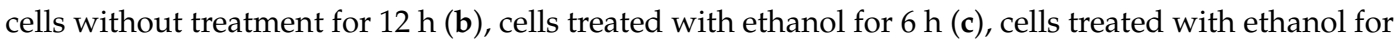
$12 \mathrm{~h}(\mathrm{~d})$, cells treated with limonene (1 MIC) for $6 \mathrm{~h}(\mathbf{e})$, cells treated with limonene (1 MIC) for $12 \mathrm{~h}(\mathbf{f})$, cells treated with limonene (2 MIC) for $6 \mathrm{~h}(\mathrm{~g})$, and cells treated with limonene (2 MIC) for $12 \mathrm{~h}(\mathbf{h})$. 


\subsubsection{Effect of Limonene on Cell Membrane Permeability of L. monocytogenes}

Changes in the conductivity of the bacterial suspension can reflect changes in the permeability of the cell membrane [15]. The conductivity of the bacterial suspension in the control group increased, but the overall change was not significant, as shown in Figure 3. However, the conductivity showed a significant increasing trend in the presence of limonene (1 MIC and $2 \mathrm{MIC}$ ) for a period of time $(p<0.05)$ when compared with the control group. The increase in the membrane conductivity of the bacteria treated with limonene at 2 MIC was higher than that treated with limonene at 1 MIC.

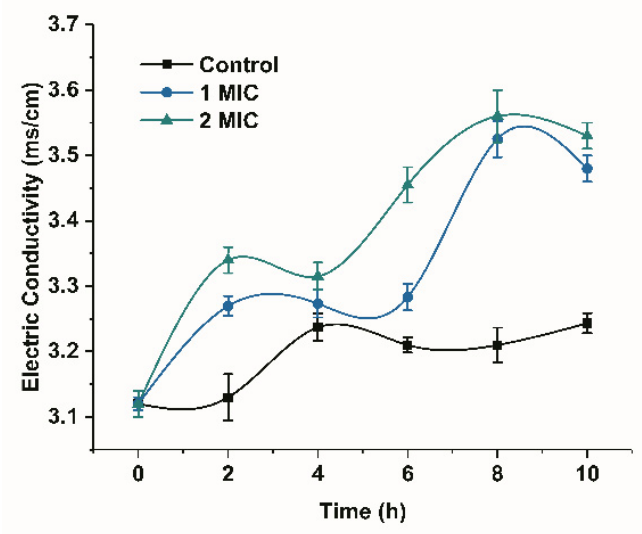

Figure 3. The inhibitory effects of limonene on the membrane conductivity of L. monocytogenes.

\subsubsection{Lethal Effect of Limonene on L. monocytogenes}

PI can enter the cell membrane of dead cells, bind to nucleic acids, and emit red fluorescence but cannot pass through the membrane of living cells [16]. Therefore, the degree of PI staining can reflect the degree of cell membrane damage and the degree of cell death. The optical MICroscopy images (Figure 4a) showed that most bacteria in the control were growing and alive, and fluorescence images (Figure $4 \mathrm{~b}$ ) indicated that no fluorescence was detected in the control group, which further confirmed that there was almost no apoptosis of bacteria. In contrast, a small amount of red fluorescence was observed in cells that were treated with limonene at 1 MIC (Figure 4c). Moreover, the red fluorescence intensities of bacteria treated with limonene at 2 MIC were significantly enhanced (Figure 4d).
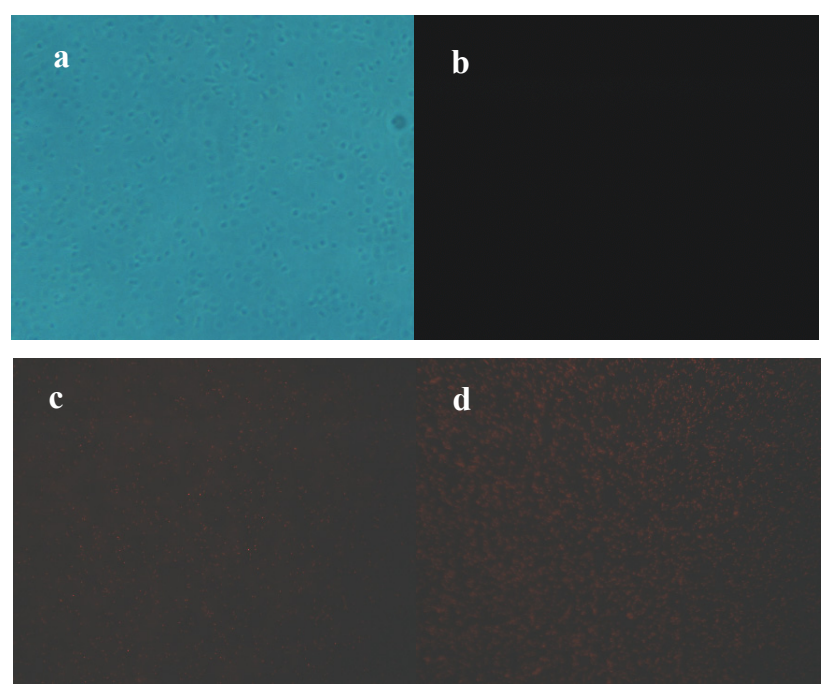

Figure 4. Observation of L. monocytogenes by using fluorescence MICroscope. L. monocytogenes under optical MICroscope (a), L. monocytogenes under fluorescence MICroscope (b), L. monocytogenes treated with limonene (MIC) for $6 \mathrm{~h}(\mathrm{c})$, L. monocytogenes treated with limonene (2 MIC) for $6 \mathrm{~h}(\mathrm{~d})$. 


\subsubsection{Nucleic Acid Leakage of L. monocytogenes}

The release of cytoplasmic components can be monitored if the bacterial membrane is damaged [17]. We monitored the change in the optical density of limonene-treated bacterial suspensions at $260 \mathrm{~nm}$ to reflect the leakage of nucleic acids since nucleic acids have a strong UV absorption at $260 \mathrm{~nm}$. The OD 260 in the control group showed no significant difference, as shown in Figure 5. The OD260 of the culture treated with limonene (1 MIC) for $9 \mathrm{~h}$ was higher than that of $3 \mathrm{~h}$, but showed no significant difference. The OD 260 significantly increased $(p<0.05)$ at $9 \mathrm{~h}$ as compared with $3 \mathrm{~h}$ after treating with limonene (2 MIC).

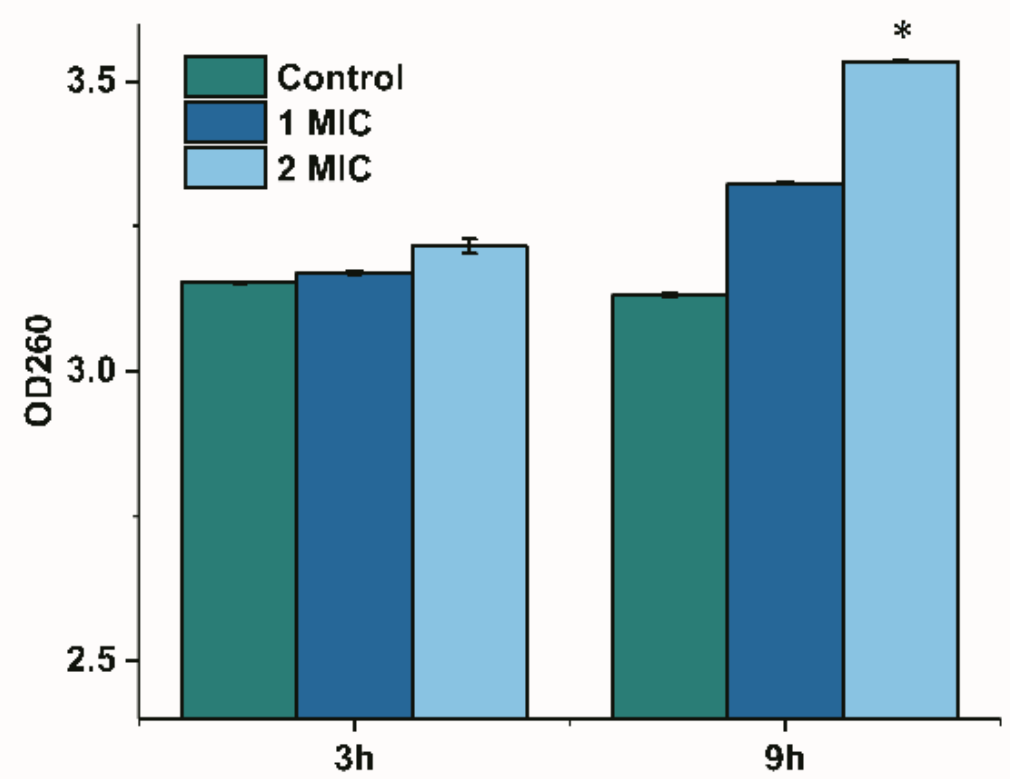

Figure 5. Changes of OD 260 of L. monocytogenes.

\subsubsection{Effect of Limonene on the Proteins of L. monocytogenes}

The damage of limonene on the cell membrane of L. monocytogenes was further explored by determining the content of intracellular soluble protein in cells, and SDS-PAGE verified the results [18]. As shown in Figure 6A, the protein concentration of the control group increased with the growth of bacteria during $0-9 \mathrm{~h}$ and then decreased at $12 \mathrm{~h}$. The addition of limonene (1 MIC) caused a sharp decrease in the protein concentration of L. monocytogenes from $0-12 \mathrm{~h}(p<0.05)$. The protein concentration of the control group was significantly higher than that of the treatment group $(p<0.05)$. As seen from the gel electrophoresis image (Figure 6B), the protein band corresponding to the limonene (1 MIC) treatment was reduced when compared with that corresponding to the control group.

\subsubsection{Effect of Limonene on ATP concentration and ATPase}

Figure 7 shows the effect of limonene on the ATP concentration and ATPase of L. monocytogenes. The addition of limonene resulted in a decrease in $\mathrm{Na}^{+} \mathrm{K}^{+}$-ATPase and $\mathrm{Ca}^{2+}$-ATPase over $24 \mathrm{~h}$, as shown in Figure $7 \mathrm{a}, \mathrm{b}$. The $\mathrm{Na}^{+} \mathrm{K}^{+}$-ATPase activity was extremely reduced in the $0-8 \mathrm{~h}$ group $(p<0.01)$ and was significantly lower in the $4-12 \mathrm{~h}$ group than in the control group $(p<0.05)$. In addition, the $\mathrm{Ca}^{2+}$-ATPase activity was extremely reduced in the $0-12 \mathrm{~h}$ group and it was significantly lower in the $4-24 \mathrm{~h}$ group than in the control group $(p<0.05)$. Simultaneously, in Figure $7 \mathrm{c}$, we observed that the ATP content showed a downward trend. At 8-16 h, the ATP content of L. monocytogenes that was exposed to limonene $(1 \mathrm{MIC})$ was significantly decreased $(p<0.05)$. 


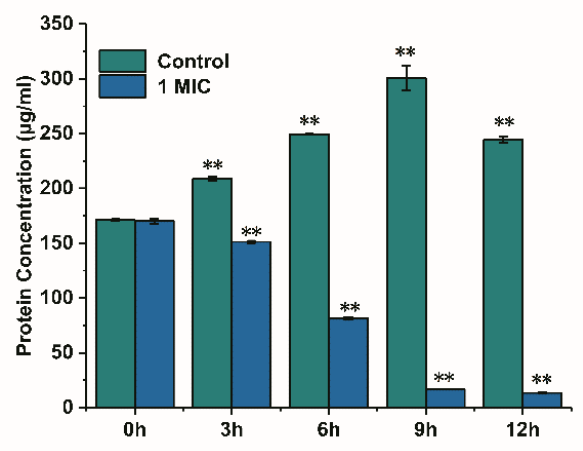

(A)

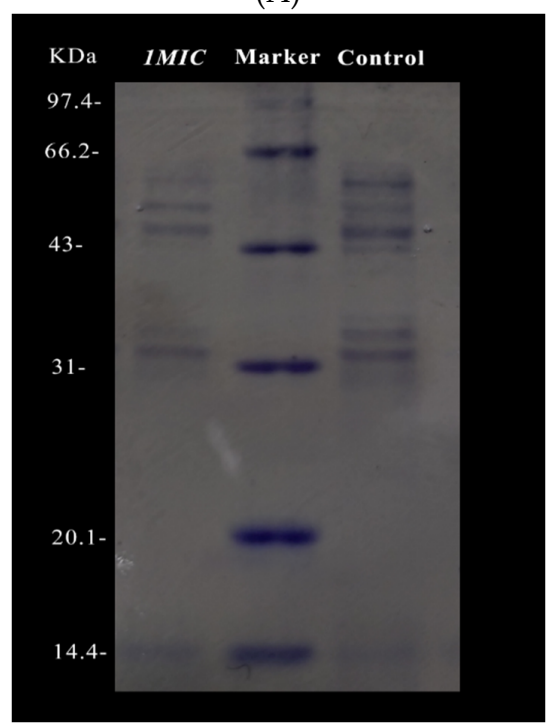

(B)

Figure 6. Effect of limonene on protein concentration of L. monocytogenes (A). The gel electrophoresis image of intracellular protein in L. monocytogenes cutured for $6 \mathrm{~h} \mathrm{(B).}$
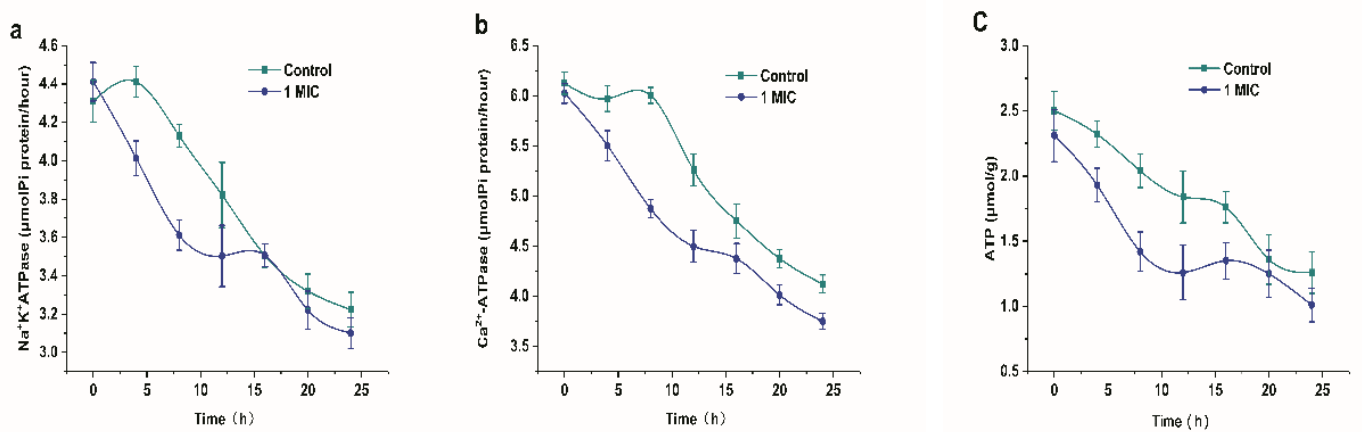

Figure 7. Changes in $\mathrm{Na}^{+}-\mathrm{K}^{+}$-ATPase (a) and $\mathrm{Ca}^{2+}$-ATPase (b) activities of L. monocytogenes. The effect of Limonene on ATP concentration of L. monocytogenes (c).

\subsubsection{Effect of Limonene on Respiratory Chain Complex I V of L. monocytogenes}

Respiratory chain enzyme complexes are proteins that are related to oxidative phosphorylation. Complex I (NADH-ubiquinone oxidoreductase), complex II (succinate dehydrogenase), complex III (ubiquinol-cytochrome c reductase), complex IV (cytochrome oxidase complex), and complex V (ATP synthase) are mainly included as the respiratory chain complexes. The respiratory function can be 
directly or indirectly reflected by the activity of respiratory chain complexes [19]. Figure 8 shows the position of the respiratory chain complex in the respiratory chain. Figure 9 shows the changes in the $\mathrm{I} \sim \mathrm{V}$ activity of the L. monocytogenes respiratory chain complex with time. The activity of complexes $\mathrm{I} \sim \mathrm{V}$ of the L. monocytogenes respiratory chain showed a downward trend. In addition, the activity of respiratory chain complex I and complex $\mathrm{V}$ treated with limonene at 8-24 $\mathrm{h}$ was significantly lower than that of the control group $(p<0.05)$.

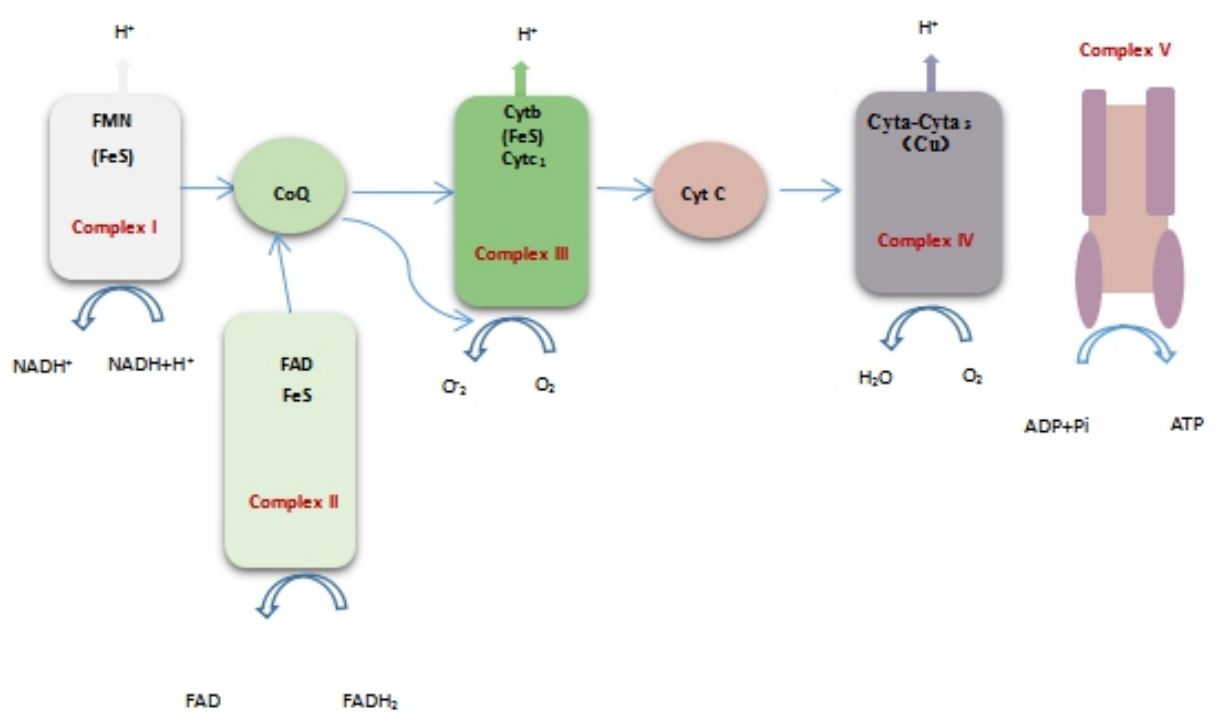

Figure 8. Oxidative phosphorylation system.
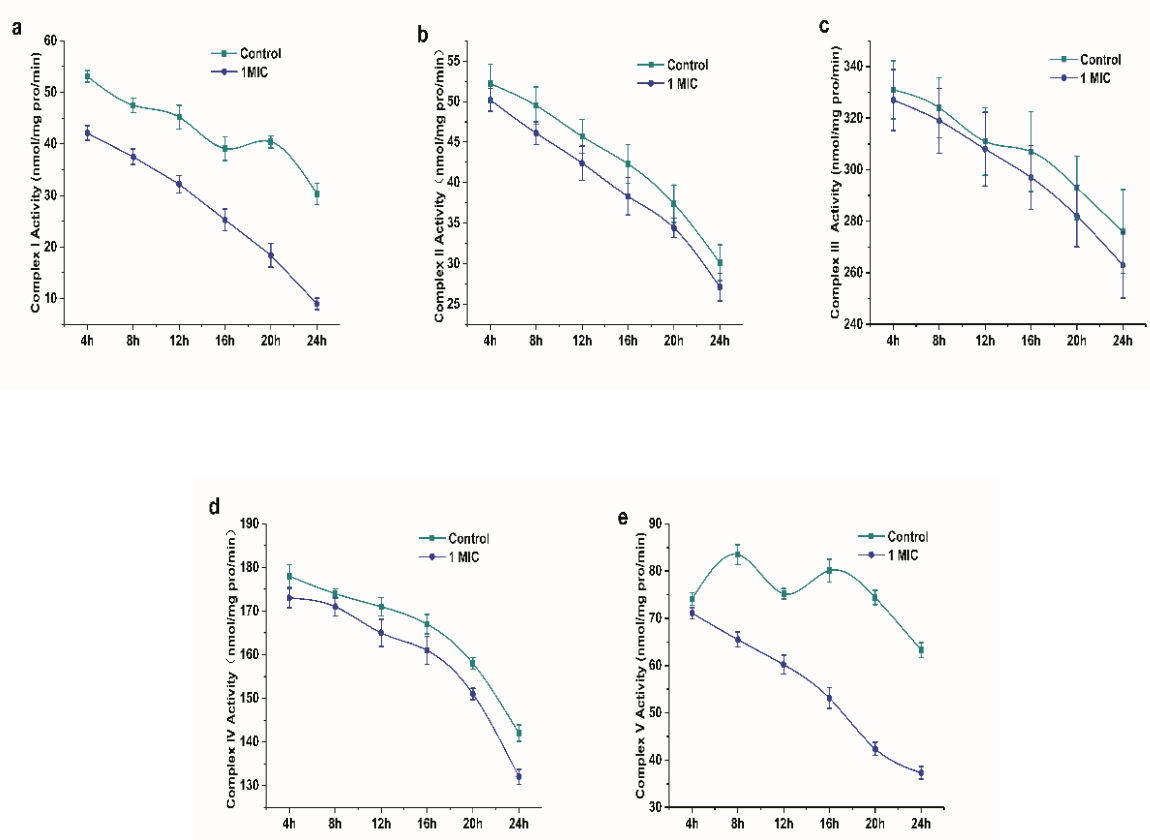

Figure 9. Changes in the activity of respiratory chain complex I V of L. monocytogenes. (a) complex I, (b) complex II, (c) complex III, (d) complex IV, and (e) complex V.

\subsubsection{Effect of Limonene on Differential Protein Expression of Respiratory Chain Complex of L. monocytogenes}

Table 2 shows the effects of limonene on the expression of respiratory chain-related complexes. The results indicated that the protein units of complexes I and IV were slightly downregulated in different proteins that were treated with limonene for $0 \mathrm{~h}$. The protein units of complexes I, III, IV, 
and $\mathrm{V}$ were significantly downregulated at $8 \mathrm{~h}$. Among the differentially expressed proteins that were treated with limonene for $24 \mathrm{~h}$, complexes III, IV, and V were significantly downregulated, and some of the protein units in complexes I and II were downregulated. It can be seen that the damage of limonene to the respiratory chain of bacteria showed an increasing trend with the prolongation of treatment time.

Table 2. Effects of Limonene on Differential Protein Expression of Respiratory Chain Complex of $L$. monocytogenes.

\begin{tabular}{|c|c|c|c|c|c|}
\hline \multirow{2}{*}{ Accession $^{a}$} & \multirow{2}{*}{ Description $^{b}$} & \multicolumn{3}{|c|}{ Fold $^{c}$} & \multirow{2}{*}{$\begin{array}{l}\text { mitochondria } \\
1 \text { Complexes } \\
\end{array}$} \\
\hline & & $0 \mathrm{~h}$ & $8 \mathrm{~h}$ & $24 \mathrm{~h}$ & \\
\hline Unigene6313_CK_0A & V-type proton ATPase subunit & 0.93 & 1.08 & 1.17 & Complex V \\
\hline Unigene2707_CK_0A & V-type proton ATPase subunit & 0.86 & 0.54 & 0.51 & Complex V \\
\hline CL3974.Contig1_CK_0A & ATP synthase subunit & 1,02 & 0.66 & 0.62 & Complex V \\
\hline CL2659.Contig1_CK_0A & ATP synthase subunit & 1.07 & 0.99 & 0.72 & Complex V \\
\hline CL1630.Contig1_CK_0A & ATP synthase subunit & 1.15 & 0.92 & 0.77 & Complex V \\
\hline CL1719.Contig1_CK_0A & V-type proton ATPase subunit & 0.97 & 0.94 & 0.83 & Complex V \\
\hline CL3569.Contig2_CK_0A & ATP synthase complex subunit & 1.01 & 0.62 & 0.29 & Complex V \\
\hline Unigene2720_CK_0̄A & ATP synthase subunit & 1.09 & 0.92 & 0.82 & Complex V \\
\hline CL2386.Contig2_CK_OA & ATP synthase subunit & 1.22 & 0.99 & 0.73 & Complex V \\
\hline Unigene2340_CK_0A & Probable cytochrome c oxidase subunit & 0.98 & 0.71 & 0.65 & Complex IV \\
\hline Unigene7527_CK_0A & Cytochrome c oxidase subunit & 1.27 & 0.89 & 0.67 & Complex IV \\
\hline CL3277.Contig1_CK_0A & Cytochrome c oxidase subunit & 0.91 & 0.72 & 0.59 & Complex IV \\
\hline CL594.Contig2_CK_0A & Ubiquinol-cytochrome $\mathrm{c}$ reductase complex subunit & 0.99 & 0.59 & 0.48 & Complex III \\
\hline CL3198.Contig1_CK_0A & Succinate dehydrogenase iron-sulfur subunit & 1.05 & 0.82 & 0.62 & Complex II \\
\hline CL1338.Contig1_CK_0A & Succinate dehydrogenase cytochrome B subunit & 0.96 & 1.09 & 1.62 & Complex II \\
\hline CL3139.Contig2_CK_0A & PX domain-containing protein & 1.22 & 1.26 & 1.37 & Complex II \\
\hline Unigene3114_CK_0A & NADH-ubiquinone oxidoreductase $9.5 \mathrm{k}$ Da subunit & 0.99 & 0.59 & 0.48 & Complex I \\
\hline CL3590.Contig2_CK_0A & Lactobacillus shifted protein & 0.97 & 0.83 & 0.71 & Complex I \\
\hline Unigene4104_CK_0A & NADH-ubiquinone oxidoreductase subunit & 1.03 & 0.87 & 0.63 & Complex I \\
\hline Unigene11357_CK_0A & NADH-ubiquinone oxidoreductase subunit & 0.97 & 0.65 & 0.79 & Complex I \\
\hline Unigene13799_CK_0A & NADH-ubiquinone oxidoreductase subunit & 1.03 & 1.18 & 0.72 & Complex I \\
\hline CL1094.Contig4_CK__OA & NADH-ubiquinone oxidoreductase subunit & 0.89 & 1.05 & 1.33 & Complex I \\
\hline CL1528.Contig4_CK_0A & NADH-ubiquinone oxidoreductase subunit & 0.99 & 1.17 & 1.42 & Complex I \\
\hline CL4703.Contig1_CK_0A & NADH dehydrogenase subcomplex & 0.70 & 1.19 & 1.28 & Complex I \\
\hline Unigene11357_CK_0A & External alternative NADH-ubiquinone oxidoreductase & 1.08 & 1.17 & 1.54 & Complex I \\
\hline CL3151.Contig2_CK_0A & NADH-ubiquinone oxidoreductase subunit & 1.38 & 0.94 & 0.86 & Complex I \\
\hline Unigene4104_CK_0A & NADH-ubiquinone oxidoreductase subunit & 1.08 & 0.96 & 0.79 & Complex I \\
\hline CL2913.Contig2_CK_0A & NADH-ubiquinone oxidoreductase subunit & 0.89 & 0.81 & 0.69 & Complex I \\
\hline
\end{tabular}

\section{Discussion}

This study explored the antibacterial activity and its mechanism of limonene against L. monocytogenes. Anis Ben Hsouna et al. [14] found that limonene was a main component in C. limon essential oil (ClEO) by GC-MS, and the antibacterial activity of C. limon essential oil was assessed by evaluating the inhibition zone (IZ) and determining the MIC values. Among Gram-positive bacteria, the highest inhibitory zone was observed against L. monocytogenes $(26 \mathrm{~mm})$, and the MIC value was $0.039 \pm 0.3 \mathrm{mg} / \mathrm{mL}$. In this study, the results of MIC and the growth curves of L. monocytogenes indicated that limonene had a significant inhibitory activity and it could effectively inhibit the growth and reproduction of L. monocytogenes. However, the MIC of Levofloxacin Hydrochloride $(0.625 \mathrm{~mL} / \mathrm{L})$ was higher than the MIC of limonene $(20 \mathrm{~mL} / \mathrm{L})$, which indicated that limonene was slightly less susceptible than Levofloxacin Hydrochloride against L. monocytogenes. The efflux pump is a kind of membrane transport protein, which is widely existed in L. monocytogenes, and can discharge antibiotics and other antimicrobial compound out of the cells to adapt to changes in the environment, so that the drug concentration in the bacteria is always kept at a low level, thus producing drug resistance. It can be speculated that L. monocytogenes may be tolerant to limonene [20].

The SEM images clearly showed that limonene could destroy the normal morphology of L. monocytogenes. The destruction of the cell wall and cell membrane could further lead to the leakage of some intracellular substances, such as extravasation of protoplasms, thus leading to cell 
death. A similar report revealed that the cell structure of Pseudomonas aeruginosa treated with limonene changed significantly, and the cells appeared to be sticky, swelled, and lysed, which was similar to the results of this experiment [21].

The cell membrane is an important protective barrier of bacteria [22]. When bacteria encounter strong bacteriostatic agents, the cell membranes of bacteria are destroyed, which causes the internal electrolyte to leak into the culture medium, and the conductivity of the culture medium then increases [23]. In this study, the conductivity was observed to significantly increase, which indicated that limonene could result in leakage of bacterial contents and change the permeability of the cell membrane, increasing the conductivity. When the cell membrane is intact, PI is blocked from binding to nucleic acids in the cell. PI can enter the cell and combine with nucleic acids, exhibiting red fluorescence, once the cell membrane is destroyed. Yan, F et al. [24] revealed that AACS can reduce cell viability by causing cell membrane rupture or increased permeability, thereby facilitating PI entry into cells and binding to nucleic acids. They also believed that the fluorescence was related to the concentration of AACS. The PI fluorescence staining results indicated that limonene treatment caused damage to the L. monocytogenes cell membrane and, as the concentration of limonene increased, the degree of damage to the cell membrane increased, eventually leading to cell death. The results were consistent with the results of the conductivity measurements.

We found an obvious increase in the optical density at $260 \mathrm{~nm}$ of the culture that was treated with limonene (1 MIC and $2 \mathrm{MIC}$ ), which showed that nucleic acids of L. monocytogenes were leaked out of the cell after treatment of limonene. Simultaneously, the protein concentration in L. monocytogenes was noticeably decreased after the addition of limonene (1 MIC). In addition, protein bands that were treated with limonene were lighter than that of the control group, which indicated that limonene could lead to the proteins leakage through cell membranes and play an antibacterial effect by affecting protein expression. A similar report revealed that $\varepsilon$-poly-lysine resulted in cell leakage, which was associated with the loss of intracellular materials (DNA, protein) [15]. Our experiments demonstrated that limonene treatment caused significant and irreversible damage to the bacterial structure and cell membrane permeability, thus resulting in the leakage of nucleic acids and proteins from cells.

ATPase plays a major role in that regulation of ion balance inside and outside mitochondrial membranes and energy metabolism [25,26]. Among them, $\mathrm{Na}^{+}-\mathrm{K}^{+}$-ATPase is crucial in the transmembrane transport of sodium and potassium ions and maintaining the permeability of the cell membranes [27]. $\mathrm{Ca}^{2+}$-ATPase can catalyse the hydrolysis of ATP on the inner side of the plasma membrane, which is significant in releasing energy and maintaining a low concentration of free $\mathrm{Ca}^{2+}$ in the cells [15]. Reference [28] reported that a rapid decrease in $\mathrm{Na}^{+}-\mathrm{K}^{+}-\mathrm{ATPase}$ activity could result in a difference in the $\mathrm{H}^{+}$gradient inside and outside the cell membrane, thereby altering the permeability of the cell membrane. In addition, the decrease in $\mathrm{Ca}^{2+}-\mathrm{Mg}^{2+}-\mathrm{ATPase}$ activity will inevitably affect the function of the $\mathrm{Ca}^{2+}$ pump, break the balance of $\mathrm{Ca}^{2+}$ in cells, and even lead to intracellular $\mathrm{Ca}^{2+}$ overload, thus causing cell apoptosis [29]. ATP is the most basic carrier of energy conversion in living organisms, and the change in its content is directly related to the energy metabolism of the cells. This result indicated that the ATP concentration of L. monocytogenes exposed to limonene was significantly decreased, which could be due to the decrease in intracellular ATPase activity. Based on the above results, it can be inferred that limonene could lower the enzyme activity, inhibit the respiration, and break the ATP balance of L. monocytogenes. In addition, the permeability of the cell membrane was increased, so the energy and key substances that are required for the growth and reproduction of the cell cannot be synthesized in time, which ultimately leads to cell death.

The respiratory chain of L. monocytogenes located on the plasma membrane is a system of electrons that transfers electrons from $\mathrm{NADH}$ or $\mathrm{FADH}_{2}$ to oxygen, being accompanied by the production of $\mathrm{O}_{2}$ and ATP. Lorena Tapia et al. [30] analysed the changes in enzymes related to respiratory chain complexes after 13-EPI-sclareol treatment. Among them, NADH oxidase and cytochrome C reductase activities decreased, while the activities of coenzyme $Q$ reductase and cytochrome $C$ oxidase were not affected. These results indicated that the target site of 13-EPI-perillanol resided between coenzyme $Q$ 
and cytochrome $\mathrm{C}$. It should be noted in this study that the activity of respiratory chain complexes of L. monocytogenes decreased to different degrees. We inferred that limonene might attenuate respiration by inhibiting the activity of the respiratory chain complex, blocking the transmission of electrons from $\mathrm{NADH}$ to coenzyme Q, which might be an important cause of the blockage of ATP synthesis.

We found that the expression of the complex I subunit (CL1094.Contig4_CK_0A, CL1528.Contig4_CK_0A, CL4703.Contig1_CK_0A, Unigene11357_CK_0A), which is responsible for obtaining two electrons from NADH and transferring them to coenzyme $Q$ via ferritin, was significantly upregulated [31], which indicated that more electrons would be transported from $\mathrm{NADH}$ into the respiratory chain of L. monocytogenes treated with limonene. Meanwhile, cytochrome (CL594.Contig2_CK_0A), one of the components of complex III, and cytochrome oxidase subunit (Unigene2340_CK_0A, Unigene7527_CK_0A, CL3277.Contig1_CK_0A), comprising the component of complex IV, were significantly downregulated, which indicated that the respiratory chain of L. monocytogenes treated with limonene was blocked and electrons accumulated in the respiratory chain. In addition, most of the ATP synthase subunits in complex V were significantly downregulated, indicating that ATP synthesis was blocked, which was consistent with the decrease in ATP content that is shown in Figure 7c. V-type proton ATPase subunit (Unigene6313_CK_0A) in complex V was significantly downregulated at $24 \mathrm{~h}$. The V-type proton ATPase is an ATPase that relies on the energy produced by the hydrolysis of ATP to produce an electrochemical gradient across the membrane and it regulates the $\mathrm{pH}$ inside and outside the cell. The high expression of V-ATPase will form a MICroenvironment near the cells, and a high concentration of extracellular $\mathrm{H}^{+}$will enter normal cells with a concentration gradient, which will cause necrosis and apoptosis of normal cells [32]. As shown in Figure 9, previous studies showed that limonene significantly inhibited the activity of respiratory chain complexes I $\sim \mathrm{V}$ of $L$. monocytogenes. The site of inhibition of bacterial respiration might exist in the process of NADH transfer to coenzyme $Q$ in the electron transfer chain. According to the significant difference in protein expression, limonene induced tremendous changes in the expression of the respiratory chain enzyme complex proteins. The results showed that limonene could affect the respiratory function and the energy level of L. monocytogenes by inhibiting the proliferation of L. monocytogenes respiratory chain complex proteins, thus leading to bacterial death.

\section{Materials and Methods}

\subsection{Bacterial Strains and Chemicals}

Limonene ((+)-Limonene) was purchased from Tokyo Chemical Industry Co., Ltd. (Tokyo, Japan) and then emulsified in 20\% ethanol. Levofloxacin Hydrochloride Eye drops was purchased from Guangdong Hongying Technology Co., Ltd. (Foushan, China). Tryptic Soy Broth (TSB) was acquired from Guangdong Huankai MICrobial Sci. \& Tech. Co., Ltd. (Guangzhou, China) (filtered twice and autoclaved at $121{ }^{\circ} \mathrm{C}$ before inoculation). PI was purchased from Jiangsu KeyGEN BioTECH Corp., Ltd. (Nanjing, China). The Bradford Protein Assay Kit was acquired from Beyotime Institute of Biotechnology (Shanghai, China). The Coomassie Brilliant Blue R-250 and Complex Activity Detection Kit were purchased from Solarbio Science \& Technology Co., Ltd., (Beijing, China). Jiancheng Bioengineering Institute (Nanjing, China) provided the ATPase assay kit and the ATP assay kit. Guangdong Huankai MICrobial Sci. \& Tech. Co., Ltd. (Guangzhou, China) provided the strain L. monocytogenes FSCC 178006 (Lot number 10068B) and it was activated in TSB at $37^{\circ} \mathrm{C}$ with shaking for $24 \mathrm{~h}$. Limonene was of Specific grade. All other chemicals were of analytical grade.

\subsection{Antibacterial Susceptibility and Determination of Bacterial Growth Curves}

\subsubsection{Determination of minimum Inhibitory Concentration (MIC)}

The agar dilution method was applied to examine the antimicrobial susceptibility of limonene against L. monocytogenes [33]. Limonene and Levofloxacin Hydrochloride (dissolved in 20\% ethanol, $v / v$, 
shaken in an oscillator for $2 \mathrm{~min}$.) were incubated with L. monocytogenes $\left(10^{6} \sim 10^{7} \mathrm{CFU} \mathrm{mL}{ }^{-1}\right)$ on tryptic soy agar plates at a final concentrations of $40,20,10,5,2.5,1.25,0.625$, or $0 \mathrm{~mL} / \mathrm{L}$ for $24 \mathrm{~h}$ at $37^{\circ} \mathrm{C}$. Each group (limonene-treated and untreated) included three biological replicates. The groups with sterile water and ethanol were marked as blank control and negative control, respectively. The groups with Levofloxacin Hydrochloride were marked as a positive control. The minimum dilution concentration for invisible bacterial growth was defined as the MIC [34].

\subsubsection{Determination of Bacterial Growth Curves of L. monocytogenes}

The growth curve of L. monocytogenes was tested by the ultraviolet spectrophotometry method [35]. First, the bacterial solution was cultured to logarithmic growth phase (approximately $10^{6} \sim 10^{7} \mathrm{CFU} / \mathrm{mL}$ ) and then inoculated in TSB medium at a $2 \%$ dosage. Afterwards, limonene was added to the TSB medium at final concentrations of 1 MIC and 2 MIC. Sterile water and ethanol $(20 \%, v / v)$ were used as controls. Subsequently, the bacterial suspension was incubated at $37^{\circ} \mathrm{C}$ and shaken at $150 \mathrm{rpm}$. Finally, the absorbance at $600 \mathrm{~nm}$ was determined by an ultraviolet spectrophotometer (TU1810, Beijing Purkinje General Instrument Co., Ltd., Beijing, China) every $1 \mathrm{~h}$.

\subsection{Antibacterial Mechanism}

\subsubsection{Scanning Electron MICroscope (SEM) Analysis}

The influence of limonene on the cell morphology of L. monocytogenes was examined by SEM (S-4800, Hitachi, Tokyo, Japan) [36]. The L. monocytogenes cells in the logarithmic growth phase were incubated with limonene (1 MIC and $2 \mathrm{MIC}$ ) for $6 \mathrm{~h}$ and $12 \mathrm{~h}$ at $37^{\circ} \mathrm{C}$ in TSB. Sterile water and ethanol were used as controls. Afterwards, the suspension was washed and centrifuged (6000 rpm, $10 \mathrm{~min}$.) with phosphate buffer solution (0.1 M, PBS, pH 7.2) three times. The cells were sequentially dehydrated with $20 \%, 40 \%, 60 \%, 80 \%$, and $100 \%$ ethanol solution. Subsequently, the cells were collected and precooled for $2 \mathrm{~h}$ at $-20^{\circ} \mathrm{C}$. Subsequently, the cells were dried for $12 \mathrm{~h}$ by a freeze dryer (Han Mei Ecology Instrument Co., Ltd., Beijing, China). Finally, the samples were sputter-coated with gold under vacuum and then observed.

\subsubsection{Effect of Limonene on Cell Membrane Permeability of L. monocytogenes}

The influence of limonene on the membrane permeability of L. monocytogenes was examined by measuring the conductivity [37]. Limonene (1 MIC and $2 \mathrm{MIC}$ ) was added to the bacterial solution at logarithmic phase and then cultured at $37^{\circ} \mathrm{C}$. Sterile water was marked as a control. The bacterial suspension ( $5 \mathrm{~mL}$, collected at $0,2,4,6,8,10 \mathrm{~h})$ was centrifuged at $6000 \mathrm{rpm}$ for $10 \mathrm{~min}$. Finally, the supernatant was diluted five times, and the conductivity was determined by a conductivity meter (Mettler Toledo, Switzerland).

\subsubsection{Determination of Cell Death of L. monocytogenes}

Propidium iodide staining and inverted fluorescence MICroscopy (MOTIC CHINA GROUP CO., LTD., Fujian, Xiamen, China) were used to identify cell death [24]. The cells that were grown to the logarithmic growth phase were cultured with $1 \mathrm{MIC}$ limonene (1 MIC and $2 \mathrm{MIC}$ ) for $6 \mathrm{~h}$ at $37^{\circ} \mathrm{C}$ and then centrifuged at $2000 \mathrm{rpm}$ for $5 \mathrm{~min}$. at $4{ }^{\circ} \mathrm{C}$. Afterwards, the cells were washed three times and then resuspended in $1 \times$ buffer. Subsequently, the initial concentration was adjusted to $1 \times 10^{6} \mathrm{CFU} / \mathrm{mL}$. Subsequently, $95 \mu \mathrm{L}$ of the bacterial suspension was supplemented with $5 \mu \mathrm{L}$ of PI at room temperature for $5 \mathrm{~min}$. Sterile water was used as a control. Finally, $10 \mu \mathrm{L}$ of the bacterial suspension was observed and then photographed under an inverted fluorescence MICroscope (excitation wavelength $536 \mathrm{~nm}$, emission wavelength $617 \mathrm{~nm}$ ). 


\subsubsection{Nucleic Acid Leakage of L. monocytogenes}

The bacterial suspension was separated into several flasks. Except for the control, L. monocytogenes cells that were grown to the logarithmic growth phase were treated with limonene (1 MIC and 2 MIC) and then cultivated at $37^{\circ} \mathrm{C}$ in a constant temperature incubator shaker (Ao Hua Instrument Co., Ltd., Changzhou, China). Sterile water was used as a control. The bacterial suspension ( $5 \mathrm{~mL}$, collected at $3 \mathrm{~h}$ and $9 \mathrm{~h}$ ) was centrifuged at $6000 \mathrm{rpm}$ for $10 \mathrm{~min}$. The precipitation was discarded, and the supernatant of $3 \mathrm{~mL}$ was removed from the centrifugal tubes. Finally, a MICroplate reader determined the absorbance of DNA and RNA macromolecule substances in the supernatant (Flash Spectrum Biological Technology Co., Ltd., Shanghai, China) at $260 \mathrm{~nm}$ [18].

\subsubsection{Determination of Protein Concentration and Leakage of Protein}

\section{Determination of Protein Concentration}

Cells that were grown to the logarithmic growth phase were treated with limonene (1 MIC) to determine changes in the protein concentration after limonene treatment, and then collected after incubating for $0,3,6,9$, and $12 \mathrm{~h}$ at $37^{\circ} \mathrm{C}$. Sterile water was used as a control. The bacterial suspension $(5 \mathrm{~mL})$ was centrifuged $\left(6000 \mathrm{rpm}, 10 \mathrm{~min} ., 4^{\circ} \mathrm{C}\right)$, and the precipitate was washed three times with PBS (0.1 M, pH 7.4). The prepared bacterial cells were resuspended in $5 \mathrm{~mL}$ of PBS, and the cells were lysed by lysozyme $(0.1 \mathrm{mg} / \mathrm{mL})$ for $30 \mathrm{~min}$. Subsequently, the bacterial cells were further broken by ultrasonic treatment (power $300 \mathrm{~W}$, ultrasound $4 \mathrm{~s}$, interval $5 \mathrm{~s}$ ) for $10 \mathrm{~min}$. in an ice bath. Subsequently, the bacterial cells were centrifuged, and the soluble proteins in the supernatant were collected. Finally, Bradford by a MICroplate reader quantified the protein contents of the samples (Flash Spectrum Biological Technology Co., Ltd., Shanghai, China) $[19,38]$.

\section{Leakage of Proteins}

The protein leakage of L. monocytogenes treated with limonene for $6 \mathrm{~h}$ was tested by sodium dodecyl sulfate-polyacrylamide gel electrophoresis (SDS-PAGE). The specific methods were as follows. First, the soluble protein in the supernatant treated with limonene (1 MIC) for $6 \mathrm{~h}$ was collected. Sterile water was marked as a control, and the amount of protein leakage from L. monocytogenes cells was then tested while using SDS-PAGE. Twenty MICrolitres of the prepared $5 \times$ loading buffer was mixed with $5 \mu \mathrm{L}$ of the protein sample in tubes, and the protein was denatured in boiling water for $5 \mathrm{~min}$; then, $10 \mu \mathrm{L}$ of the sample was loaded. Moreover, the concentrations of the separating gel and concentrating gel were $15 \%$ and $5 \%$, respectively. The starting voltage was $60 \mathrm{~V}$ and the voltage of the sample changed to $120 \mathrm{~V}$ after entering the separating gel. After completing the electrophoresis, the gel was removed and then stained with Coomassie Brilliant Blue R-250, and the separated protein bands were obtained after decolorization [39].

\subsubsection{Effect of Limonene on the ATP}

Effects of Limonene on the Activity of ATPase

Changes in the ATPase activity of L. monocytogenes were tested while using an ATPase assay kit and the absorbance values of the extract at $660 \mathrm{~nm}$ were determined by a UV spectrophotometer (Metash Instruments Co., Ltd., Shanghai, China). The enzyme activity unit was defined as the amount of inorganic phosphorus produced by ATP enzymatic decomposition of ATP per milligram of protein per hour.

\section{Determination of ATP Concentration}

Limonene at a final concentration of 1 MIC was added to the prepared bacterial suspension and then cultured at $37^{\circ} \mathrm{C}$ for $0,4,8,12,16,20$, and $24 \mathrm{~h}$, and then centrifuged at $6000 \mathrm{rpm}$ for $10 \mathrm{~min}$. to collect the bacteria precipitate. Sterile water was used as a control. The acquired bacteria precipitate 
was treated, as previously described in 4.3.5.1, to obtain the bacterial lysate. Finally, the intracellular ATP concentration was tested while using the ATP assay kit and then determined by a MICroplate reader (Flash Spectrum Biological Technilogy Co., Ltd., Shanghai, China) at $636 \mathrm{~nm}$ [40].

\subsubsection{Effects of Limonene on Respiratory Chain Complex I V}

The Complex Activity Detection Kit was used to determine the effect of limonene on the respiratory chain complexes I V of L. monocytogenes. The specific steps were, as follows: first, $5 \times 10^{6}$ bacterial cells of the control group (sterile water) and the experimental group (1 MIC) cultured for 4, 8, 12, 16, 20, and $24 \mathrm{~h}$ were collected; then, $1 \mathrm{~mL}$ of lysis buffer was added, and the cells were homogenized on ice with a homogenizer. The homogenate was centrifuged $\left(4^{\circ} \mathrm{C}, 600 \mathrm{~g}, 10 \mathrm{~min}\right.$.), and the supernatant was placed into another centrifugal tube and then centrifuged by centrifugation $\left(4^{\circ} \mathrm{C}, 11000 \mathrm{~g}, 15 \mathrm{~min}\right.$.). Next, $400 \mu \mathrm{L}$ of lysis buffer was added to the precipitate, and the cells were broken by ultrasonic treatment (power 20\%, ultrasonic $5 \mathrm{~s}$, interval $10 \mathrm{~s}$, repetition 15 times). The OD340, OD605, OD550, OD550, and OD660 were measured by a UV spectrophotometer to determine the enzyme activity of the respiratory chain complexes $(\mathrm{I} \sim \mathrm{V})$, respectively.

4.3.8. Effects of Limonene on the Differential Protein Expression of the Respiratory Chain Complex of L. monocytogenes

The respiratory chain complex proteins were extracted according to 4.3 .7 references. Protein samples were reduced and alkylated with iodoacetamide (carbamidomethylated), digested with trypsin, and labelled with iTRAQ reagent. Subsequently, SCX chromatography separated the labelled peptides (GE Healthcare). LC-ESI-MS/MS identified the resulting peptides. Protein function descriptions were described according to the NCBI and UniProt_Swissprot databases. Differentially using expressed proteins were classified the following scale: more than 1.2-fold, and the P value was less than 0.05 .

\subsection{Statistical Analysis}

The experimental results were statistically analysed by SPSS software (version; IBM Corp., Armonk, NY, USA). The experiments were carried out in triplicate and expressed as the mean \pm SD. The significant differences were determined at a significance level of $p<0.05$. Graphs were created by Origin software (Origin Lab Co., Pro.17.0, Northampton, MA, USA).

\section{Conclusions}

The current work confirmed that limonene showed effective antibacterial activity against L. monocytogenes, but it was less susceptible than the positive control. Besides, the results showed that limonene could inhibit the growth of bacteria and even lead to death. In addition, limonene could destroy the cell wall and cell membrane, which leads to the leakage of proteins and nucleic acids. Simultaneously, limonene could inhibit ATP synthesis by inhibiting ATPase activity and respiratory chain complex activity, leading to respiratory metabolic disorders and, ultimately, cell death. In conclusion, this study showed that limonene can act as a potential inhibitor against $L$. monocytogenes. We will continue to use more advanced experimental technology to strengthen the antibacterial activity and explore the antibacterial mechanism of limonene in the future research.

Author Contributions: Y.H.: Writing—original draft; Y.H and Z.S.: Data curation; Methodology; W.C.: Project administration, Writing-review \& editing. All authors have read and agreed to the published version of the manuscript.

Funding: This study was funded by the National Natural Science Foundation of China (No. 31760480 and 31640061).

Conflicts of Interest: The authors declare that they have no conflict of interest. 


\section{References}

1. Heredia, N.; García, S. Animals as sources of food-borne pathogens: A review. Anim. Nutr. 2018, 4, 14-19. [CrossRef]

2. Rodriguez-Lazaro, D.; Gonzalez-García, P.; Gattuso, A.; Gianfranceschi, M.V.; Hernandez, M. Reducing time in the analysis of Listeria monocytogenes in meat, dairy and vegetable products. Int. J. Food MICrobiol. 2014, 184, 98-105. [CrossRef] [PubMed]

3. Orhan, Y.; Bilgehan, A.; Duygu, E.; Uner, K.; Emine, A.; Bulent, S.; Mehmet, D. Sepsis and Meningitis due to Listeria monocytogenes. Yonsei Med. J. 2007, 48, 433-439.

4. Malekmohammadi, S.; Kodjovi, K.K.; Sherwood, J.; Bergholz, T.M. Genetic and environmental factors influence Listeria monocytogenes nisin resistance. J. Appl. MICrobiol. 2017, 123, 262-270. [CrossRef] [PubMed]

5. Tompkin, R.B. Control of Listeria monocytogenes in the food-processing environment. J. Food Prot. 2002, 65, 709-725. [CrossRef] [PubMed]

6. Turgis, M.; Vu, K.D.; Dupont, C.; Lacroix, M. Combined antimicrobial effect of essential oils and bacteriocins against foodborne pathogens and food spoilage bacteria. Food Res. Int. 2012, 48, 696-702. [CrossRef]

7. Ribeirosantos, R.; Andrade, M.; Melo, N.R.D.; Sanchessilva, A. Use of essential oils in active food packaging: Recent advances and future trends. Trends Food Sci. Technol. 2017, 61, 132-140. [CrossRef]

8. Morin, P.; Caude, M.; Richard, H.; Rosset, R. Semipreparative separation of terpenoids from essential oils by high-performance liquid chromatography and their subsequent identification by gas chromatography-Mass spectrometry. J. Chromatogr. A 1986, 363, 37-56. [CrossRef]

9. Sun, J.J. D-Limonene: Safety and clinical applications. Altern. Med. Rev. 2007, 12, $259-264$.

10. Young Woo, K.; Ji, K.M.; Young, C.B.; Yeon, B.D.; Seong Kwang, L.; Seul min, C.; Duck Soo, L.; Myung Chan, C.; Kyungsil, Y.; Hyung Sik, K.; et al. Safety evaluation and risk assessment of d-limonene. J. Toxicol. Environ. Health Part B 2013, 16, 17-38.

11. Anis Ben, H.; Mohamed, T.; Riadh Ben, M.; Raoudha Mezghani, J.; Mohamed, D.; Samir, J. Chemical composition, cytotoxicity effect and antimicrobial activity of Ceratonia siliqua essential oil with preservative effects against Listeria inoculated in minced beef meat. Int. J. Food MICrobiol. 2011, 148, 66-72.

12. Celaya, L.S.; Alabrudzińska, M.H.; Molina, A.C.; Viturro, C.I.; Silvia, M. The inhibition of methicillin-resistant Staphylococcus aureus by essential oils isolated from leaves and fruits of Schinus areira depending on their chemical compositions. Acta Biochim. Pol. 2014, 61, 41-46. [CrossRef] [PubMed]

13. Lee, S.B.; Cha, K.H.; Kim, S.N.; Altantsetseg, S.; Shatar, S.; Sarangerel, O.; Nho, C.W. The Antimicrobial Activity of Essential Oil from Dracocephalum foetidum against Pathogenic MICroorganisms. J. MICrobiol. 2007, 45, 53-57. [PubMed]

14. Hsouna, A.B.; Halima, N.B.; Smaoui, S.; Hamdi, N. Citrus lemon essential oil: Chemical composition, antioxidant and antimicrobial activities with its preservative effect against Listeria monocytogenes inoculated in minced beef meat. Lipids Health Dis. 2017, 16, 146. [CrossRef] [PubMed]

15. Lin, L.; Gu, Y.; Li, C.; Vittayapadung, S.; Cui, H. Antibacterial mechanism of $\varepsilon$-Poly-lysine against Listeria monocytogenes and its application on cheese. Food Control. 2018, 91, 76-84. [CrossRef]

16. Lau, A.C.; Cui, H.; Tymianski, M. The use of propidium iodide to assess excitotoxic neuronal death in primary mixed cortical cultures. Methods Mol. Biol. 2007, 399, 15-29.

17. Chen, C.Z.; Cooper, S.L. Interactions between dendrimer biocides and bacterial membranes. Biomaterials 2002, 23, 3359-3368. [CrossRef]

18. Wang, J.; Cheng, Y.; Wu, R.; Jiang, D.; Bai, B.; Tan, D.; Yan, T.; Sun, X.; Zhang, Q.; Wu, Z. Antibacterial Activity of Juglone againstStaphylococcus aureus: From Apparent to Proteomic. Int. J. Mol. Sci. 2016, $17,965$. [CrossRef]

19. Rustin, P.; Chretien, D.; Bourgeron, T.; Gérard, B.; Rötig, A.; Saudubray, J.M.; Munnich, A. Biochemical and molecular investigations in respiratory chain deficiencies. Clin. Chim. Acta 1994, 228, 35-51. [CrossRef]

20. Francois, G.; Marc, G.; Fabrice, T.; Patrice, C.; Vincent, C.; One, M.R.J.P. Overexpression of the Novel MATE Fluoroquinolone Efflux Pump FepA in Listeria monocytogenes Is Driven by Inactivation of Its Local Repressor FepR. PLoS ONE 2014, 9, e106340.

21. Wang, J.-N.; Chen, W.-X.; Chen, R.-H.; Zhang, G.-F. Antibacterial activity and mechanism of limonene against Pseudomonas aeruginosa. J. Food Sci. Technol. 2018, 39, 1-5.

22. Hoshi, T.J.N. Carrier transport function of cell membrane. Rinsho Jpn. J. Clin. Med. 1985, 43, 725-730. 
23. Zhao, Y.; Chen, M.; Zhao, Z.; Yu, S. The antibiotic activity and mechanisms of sugarcane (Saccharum officinarum L.) bagasse extract against food-borne pathogens. Food Chem. 2015, 185, 112-118. [CrossRef] [PubMed]

24. Yan, F.; Dang, Q.; Liu, C.; Yan, J.; Wang, T.; Fan, B.; Cha, D.; Li, X.; Liang, S.; Zhang, Z. 3, 6-O-[N-(2-Aminoethyl)-acetamide-yl]-chitosan exerts antibacterial activity by a membrane damage mechanism. Carbohydr. Polym. 2016, 149, 102-111. [CrossRef] [PubMed]

25. Mt, C.R.V.; Bordons, A.; Constanti, M. Inhibitory effect of sulfur dioxide and other stress compounds in wine on the ATPase activity of Oenococcus oeni. FEMS MICrobiol. Lett. 2002, 211, 155-159.

26. Liguri, G.; Taddei, N.; Nassi, P.; Latorraca, S.; Nediani, C.; Sorbi, S. Changes in $\mathrm{Na}^{+}, \mathrm{K}^{+}$-ATPase, Ca ${ }^{2+}$-ATPase and some soluble enzymes related to energy metabolism in brains of patients with Alzheimer's disease. Neurosci. Lett. 1990, 112, 338-342. [CrossRef]

27. Lebrun, P.; Malaisse, W.J.; Herchuelz, A. $\mathrm{Na}^{+}-\mathrm{K}^{+}$pump activity and the glucose-stimulated $\mathrm{Ca}^{2+}$-sensitive $\mathrm{K}^{+}$permeability in the pancreatic B-cell. J. Membr. Biol. 1983, 74, 67-73. [CrossRef] [PubMed]

28. Pontes, Z.E.L.; Oliveira, L.S.; Baveresco, C.S.; Streck, E.L.; Dutra-Filho, C.S.; Wajner, M.; Wannmacher, C.; Wyse, A.T.S. Proline Administration Decreases $\mathrm{Na}^{+}, \mathrm{K}^{+}$-ATPase Activity in the Synaptic Plasma Membrane from Cerebral Cortex of Rats. Metab. Brain Dis. 1999, 14, 265-272. [CrossRef] [PubMed]

29. Gulcan, H.; Ozturk, I.C.; Arslan, S.J.B. Alterations in antioxidant enzyme activities in cerebrospinal fluid related with severity of hypoxic ischemic encephalopathy in newborns. Neonatology 2005, 88, 87-91. [CrossRef] [PubMed]

30. Tapia, L.; Torres, J.; Mendoza, L.; Urzúa, A.; Ferreira, J.; Pavani, M.; Wilkens, M. Effect of 13-epi-sclareol on the bacterial respiratory chain. Planta Med. 2004, 70, 1058-1063. [CrossRef]

31. Brandt, U.; Zickermann, V. Respiratory Chain Complex, I. Ency. Biol. Chem. 2013, 3, 87-91.

32. Tsuyoshi, N.; MIChael, F. The vacuolar $\left(\mathrm{H}^{+}\right)$-ATPases-Nature's most versatile proton pumps. Nat. Rev. Mol. Cell Biol. 2002, 3, 94-103.

33. Xin, L.; Yi, L.; Jing, D.; Ying, D.; Liu, B. Purification of novel bacteriocin produced by Lactobacillus coryniformis MXJ 32 for inhibiting bacterial foodborne pathogens including antibiotic-resistant MICroorganisms. Food Control 2014, 46, 264-271.

34. Manalo, R.V.M.; Josol, V.J.D.; Gloriani, N.G. The differential effects of atorvastatin co-administered with ampicillin on the bacterial growth and biofilm formation of Staphylococcus aureus. Curr. Med. Res. Prac. 2017, 7, 178-183. [CrossRef]

35. Huang, J.; Qian, C.; Xu, H.; Huang, Y. Antibacterial activity of Artemisia asiatica essential oil against some common respiratory infection causing bacterial strains and its mechanism of action in Haemophilus influenzae. Microb. Pathog. 2018, 114, 470-475. [CrossRef]

36. Yi, L.; Jing, D.; Zhang, L.; Wu, Y.; Liu, B.; Xin, L. Purification, characterization and bactericidal mechanism of a broad spectrum bacteriocin with antimicrobial activity against multidrug-resistant strains produced by Lactobacillus coryniformis XN8. Food Control 2016, 67, 53-62. [CrossRef]

37. Sun, D.; Zhang, W.; Lv, M.; Yang, E.; Zhao, Q.; Wang, W. Antibacterial activity of ruthenium (II) polypyridyl complex manipulated by membrane permeability and cell morphology. Bioorg. Med. Chem. Lett. 2015, 25, 2068-2073. [CrossRef] [PubMed]

38. Hu, W.; Li, C.; Dai, J.; Cui, H.; Lin, L. Antibacterial activity and mechanism of Litsea cubeba essential oil against methicillin-resistant Staphylococcus aureus (MRSA). Ind. Crops Prod. 2019, 130, 34-41. [CrossRef]

39. Zhang, Y.; Feng, R.; Li, L.; Zhou, X.; Li, Z.; Jia, R.; Song, X.; Zou, Y.; Yin, L.; He, C. The Antibacterial Mechanism of Terpinen-4-ol Against Streptococcus agalactiae. Curr. MICrobiol. 2018, 75, 1214-1220. [CrossRef] [PubMed]

40. Chen, W.; Tang, H.; Jiang, N.; Zhong, Q.; Hu, Y. Antibacterial Effect of Black Pepper Petroleum Ether Extract against Listeria monocytogenes and Salmonella typhimurium. J. Food Qual. 2019, 2019, 1-10. [CrossRef]

Sample Availability: Samples of the compounds are available from the authors. 